\title{
Cancer-Specific Mortality, All-Cause Mortality, and Overdiagnosis in Lung Cancer Screening Trials: A Meta-Analysis
}

\author{
Mark H. Ebell, MD, MS \\ Michelle Bentivegna, MPH \\ Cassie Hulme, MPH \\ Department of Epidemiology, College \\ of Public Health, University of Georgia, \\ Athens, Georgia
}

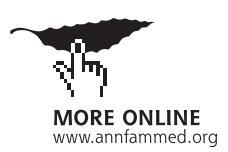

Conflicts of interest: authors report none.

\section{CORRESPONDING AUTHOR}

Mark H. Ebell, MD, MS

125 B.S. Miller Hall

UGA Health Sciences Campus

Athens, GA 30602

ebell@uga.edu

\begin{abstract}
PURPOSE Benefit of lung cancer screening using low-dose computed tomography (LDCT) in reducing lung cancer-specific and all-cause mortality is unclear. We undertook a meta-analysis to assess its associations with outcomes.

METHODS We searched the literature and previous systematic reviews to identify randomized controlled trials comparing LDCT screening with usual care or chest radiography. We performed meta-analysis using a random effects model. The primary outcomes were lung cancer-specific mortality, all-cause mortality, and the cumulative incidence ratio of lung cancer between screened and unscreened groups as a measure of overdiagnosis.
\end{abstract}

RESULTS Meta-analysis was based on 8 trials with 90,475 patients that had a low risk of bias. There was a significant reduction in lung cancer-specific mortality with LDCT screening (relative risk $=0.81 ; 95 \% \mathrm{Cl}, 0.74-0.89$ ); the estimated absolute risk reduction was $0.4 \%$ (number needed to screen $=250$ ). The reduction in all-cause mortality was not statistically significant (relative risk $=0.96 ; 95 \% \mathrm{Cl}, 0.92-1.01)$, but the absolute reduction was consistent with that for lung cancer-specific mortality $(0.34 \%$; number needed to screen $=294$ ). In the studies with the longest duration of follow-up, the incidence of lung cancer was $25 \%$ higher in the screened group, corresponding to a $20 \%$ rate of overdiagnosis.

CONCLUSIONS This meta-analysis showing a significant reduction in lung cancerspecific mortality, albeit with a tradeoff of likely overdiagnosis, supports recommendations to screen individuals at elevated risk for lung cancer with LDCT.

Ann Fam Med 2020;18:545-552. https://doi.org/10.1370/afm.2582.

\section{INTRODUCTION}

L ung cancer is an important cause of morbidity and mortality, with an estimated 228,820 new diagnoses and 135,720 deaths expected in 2020. ${ }^{1}$ Early detection has been shown to reduce disease-specific mortality for breast cancer and colorectal cancer. ${ }^{2,3}$ Although screening with chest radiography improves survival from the time of lung cancer diagnosis, this benefit is due to lead-time bias, and lung cancer-specific and all-cause mortality are not improved. ${ }^{4}$

The National Lung Screening Trial (NLST) compared low-dose computed tomography (LDCT) with chest radiography in 53,454 participants aged 55 to 74 years with at least a 30 -pack-year history of smoking who were current smokers or who had quit within the preceding 15 years. ${ }^{5}$ After a median 6.5-year follow-up, patients randomized to 3 rounds of annual screening with LDCT had a significantly lower rate of both lung cancer-specific mortality and all-cause mortality. ${ }^{5}$ The NLST results were published in 2011, and in 2013, the US Preventive Services Task Force recommended lung cancer screening using LDCT for persons aged 55 to 80 years old with a 30-pack-year smoking history who were current smokers or who had quit smoking in the past 15 years. ${ }^{6}$ 
The next 2 large randomized controlled trials, published in 2015, found no reduction in lung cancer-specific or all-cause mortality, however, with relative risks (RRs) for lung cancer-specific mortality of 1.01 (95\% CI, 0.70-1.44) in the Italian Detection and Screening of Early Lung Cancer With Novel Imaging Technology (DANTE) trial ${ }^{7}$ and 1.03 (95\% CI, 0.66-1.60) in the Danish Lung Cancer Screening Trial (DLCST). ${ }^{8}$ A 2019 meta-analysis identified only 5 studies with mortality results. ${ }^{9}$ A second meta-analysis that year reported mortality data for 9 randomized trials of lung cancer screening using $\mathrm{LDCT}_{1}{ }^{10}$ but final data for a Dutch and Belgian trial, the Nederlands-Leuvens Longkanker Screenings Onderzoek (NELSON) trial, ${ }^{11}$ were not published till February 2020 and were not included. Furthermore, this meta-analysis included data from a flawed trial, ${ }_{1}^{12}$ excluded all-cause mortality data and data from women from NELSON, and did not estimate absolute risk reductions and the number needed to screen.

We therefore performed a new meta-analysis of high-quality randomized controlled trials that addressed these limitations, with the goal of understanding the relationship of LDCT screening for lung cancer with disease-specific and all-cause mortality. Secondarily, we assessed evidence of overdiagnosis, an important potential harm of screening. ${ }^{13}$

\section{METHODS}

We performed a random effects meta-analysis of randomized controlled trials that compared screening using LDCT with a control of either chest radiography or usual care, and reported lung cancer-specific or all-cause mortality. Results for chest radiography and usual care were combined, as previous research has shown convincingly that the former has no impact on lung cancer-specific or all-cause mortality. ${ }^{4}$ The review was registered with the Prospective Register of Systematic Reviews (PROSPERO) registry of systematic reviews (number CRD42020171213) and followed Preferred Reporting Items for Systematic Reviews and Meta-analyses (PRISMA) guidelines for reporting of systematic reviews. ${ }^{14}$ The PRISMA checklist is available online.

\section{Search}

A recent meta-analysis performed a comprehensive search for randomized trials through June, 2019. ${ }^{10} \mathrm{We}$ performed a bridge search of PubMed from January 1, 2019 to February 26, 2020 using the search strategy shown in the Supplemental Appendix, available at https://www.AnnFamMed.org/content/18/6/545/suppl/ DC1/. Reference lists of all included studies were also searched. Inclusion criteria required that trials had a randomized controlled design and a low risk of bias, and compared LDCT with chest radiography or usual care in adults at elevated risk for lung cancer. We did not place any limits on language or duration of follow-up.

\section{Data Abstraction}

Abstracts were reviewed by investigators in tandem. Any abstract identified as potentially relevant by 1 of the investigators was reviewed in full, again, by at least 2 others. Decisions regarding inclusion of studies were based on the full-text review in tandem, with discrepancies resolved by discussion between the investigators. Where available, supplemental appendices and earlier reports were also reviewed for study design and quality characteristics.

Data regarding study characteristics, study quality, incidence, and mortality were abstracted in parallel by 2 investigators. Any discrepancies were resolved by consensus discussion. Data were recorded initially in a series of Google Drive worksheets (Google LLC), and the incidence and mortality data were then imported into the statistical program for analysis.

\section{Trial Quality}

We assessed trial quality using the Cochrane Risk of Bias tool. ${ }^{15}$ Investigators reviewed the trials in tandem and resolved any discrepancies by consensus discussion. If allocation concealment was not explicitly described in the methods but groups were well balanced, the trial was judged to have an unclear risk of bias.

\section{Analytic Strategy}

We performed the primary analysis using Stata version 16 (StataCorp LLC). A funnel plot was drawn to evaluate for publication bias using the metafunnel command. Heterogeneity was assessed using the $\mathrm{I}^{2}$ statistic and by visual inspection of forest plots, given that the former is unreliable when there is a small number of studies. ${ }^{16}$ For outcomes with adequate homogeneity as defined by an $\mathrm{I}^{2}$ of less than $25 \%$ or by visual inspection, we performed random effects meta-analysis using the DerSimonian and Laird model in the metan procedure in Stata. The primary outcomes were lung cancer-specific and all-cause mortality in trials judged to have a low risk of bias.

A secondary outcome was the number of cancers diagnosed during the follow-up period in screened and control groups, a metric for estimating overdiagnosis. Because most studies did not report incidence rates per 100,000 person-years, we calculated a summary estimate of the cumulative incidence ratio (total lung 
cancers divided by total population randomized) for screened and control patients in each group using the metan procedure and a random effects model. For this analysis, we included only trials with longer followup, arbitrarily defined as 8 or more years, as a short duration does not allow adequate time for undetected cancers in the control group to become symptomatic if they are destined to. ${ }^{17}$

We applied the summary estimates of relative risk to the pooled mortality rate in the control groups to determine the estimated mortality rate in the screened group, whereby the difference between mortality rates was the absolute risk reduction. The absolute risk reduction was then used to calculate the number needed to screen to prevent 1 additional lung cancer death and 1 additional all-cause death, in order to evaluate whether the magnitude of the mortality reduction was similar for these outcomes.

Because the study used only aggregate published data, human subjects review was not required.

\section{RESULTS}

Our bridge search identified 33 trials. Two were reviewed in full. One provided the final results of the NELSON trial, ${ }^{11}$ and the other provided the most recent results from the German Lung Cancer Screening Intervention (LUSI) trial ${ }^{18}$; both were included. Combination of these trials with those identified in the previous meta-analysis ${ }^{10}$ yielded a total of 9 randomized controlled trials of LDCT screening that met our inclusion criteria (see Supplemental Figure 1, available at https://www.AnnFamMed.org/content/18/6/545/ suppl/DC1/, for the PRISMA diagram). Individual study-level data for mortality and incidence are given in Supplemental Table 1 and Supplemental Table 2, respectively, both available at https://www.AnnFam Med.org/content/18/6/545/suppl/DC1/. A funnel plot (Supplemental Figure 2, available at https://www.Ann FamMed.org/content/18/6/545/suppl/DC1/) showed no evidence of publication bias.

\section{Trial Quality}

The quality of the 9 randomized controlled trials is summarized in Table $1.5,7,8,11,12,18-21$ One of these trials ${ }^{12}$ had a large imbalance between the number of patients in the screening and control groups $(3,512$ vs 3,145$)$ and provided no details regarding randomization procedures or concealment of allocation. Such a large imbalance is inconsistent with proper randomization, allocation concealment, or both, and we therefore excluded this trial from further analyses because of its high risk of bias. The trial also had only 2 years of follow-up with a total of 2 deaths due to lung cancer, so the follow-up was also judged to be inadequate.

\section{Trial Characteristics}

After excluding the trial with high risk of bias, we were left with 8 trials having a total of 90,475 patients. ${ }^{5,7,8,11,18-21}$ Characteristics of these trials are summarized in Table 2. The trials ranged in size from 2,450 to 53,454 patients, and typically recruited patients with 20 to 30 or more pack-years of smoking and who were currently smoking or had quit no more than 10 to 15 years ago. A variety of age ranges were used, most commonly aged 50 to 70 years, but beginning as young as aged 45 years and continuing until as old as aged 75 years in some studies. The lung cancer mortality in the

\section{Table 1. Quality Assessment of the 9 Trials Meeting Inclusion Criteria}

\begin{tabular}{|c|c|c|c|c|c|c|}
\hline Trial, Year & $\begin{array}{l}\text { Random } \\
\text { Sequence } \\
\text { Generation }\end{array}$ & $\begin{array}{l}\text { Allocation } \\
\text { Concealment }\end{array}$ & $\begin{array}{l}\text { Blinding of } \\
\text { Participants } \\
\text { and Personnel }\end{array}$ & $\begin{array}{l}\text { Blinding of } \\
\text { Outcome } \\
\text { Assessment }^{\mathrm{a}}\end{array}$ & $\begin{array}{l}\text { Incomplete } \\
\text { Outcome Data }\end{array}$ & $\begin{array}{l}\text { Selective } \\
\text { Reporting }\end{array}$ \\
\hline $\begin{array}{l}\text { National Lung Screen- } \\
\text { ing Trial Research } \\
\text { Team et al, }{ }^{5} 2011\end{array}$ & L & L & L & $\mathrm{L} / \mathrm{U}$ & L & L \\
\hline Infante et $\mathrm{al}_{1}^{7} 2015$ & L & u & L & $\mathrm{L} / \mathrm{U}$ & L & L \\
\hline Wille et al, ${ }^{8} 2016$ & L & L & L & $\mathrm{L} / \mathrm{U}$ & L & L \\
\hline Paci et al ${ }^{19} 2017$ & L & L & L & $\mathrm{L} / \mathrm{U}$ & L & L \\
\hline Yang et al,,$^{12} 2018$ & $\mathrm{H}$ & $\mathrm{H}$ & L & $\mathrm{L} / \mathrm{U}$ & L & L \\
\hline Doroudi et al, ${ }^{20} 2018$ & $\mathrm{~L}$ & $\mathrm{u}$ & L & $\mathrm{L} / \mathrm{U}$ & L & $\mathrm{L}$ \\
\hline Pastorino et al, 212019 & L & L & L & $\mathrm{L} / \mathrm{U}$ & L & L \\
\hline Becker et al, ${ }^{18} 2020$ & L & u & L & $\mathrm{L} / \mathrm{U}$ & L & L \\
\hline de Koning et al, ${ }^{11} 2020$ & L & u & L & $\mathrm{L} / \mathrm{U}$ & L & L \\
\hline $\begin{array}{l}\mathrm{H}=\text { high risk of bias; } \mathrm{L}=\text { lov } \\
\text { a Risk of bias for all-cause } \mathrm{m} \\
\text { Note: Quality was assessed }\end{array}$ & $\begin{array}{l}\text { sk of bias; } U=\text { unc } \\
\text { ality/risk of bias for } \\
\text { the Cochrane Risk }\end{array}$ & $\begin{array}{l}\text { Ir risk of bias. } \\
\text { ang cancer-specific m } \\
\text { f Bias Tool. }{ }^{15}\end{array}$ & & & & \\
\hline
\end{tabular}


Table 2. Characteristics of the 8 Trials Included in Quantitative Meta-Analyses

\begin{tabular}{|c|c|c|c|c|}
\hline Trial, Year & Inclusion Criteria & $\begin{array}{l}\text { Participants, } \\
\text { No. }\end{array}$ & $\begin{array}{l}\text { Lung Cancer } \\
\text { Mortality in } \\
\text { Control Group, \% }\end{array}$ & $\begin{array}{l}\text { Age at Study } \\
\text { Entry }\end{array}$ \\
\hline $\begin{array}{l}\text { National Lung } \\
\text { Screening Trial } \\
\text { Research Team } \\
\text { et al, } 2011\end{array}$ & $\begin{array}{l}\text { Aged } 55-74 \text { years, } \geq 30 \text { pack-years, current smoker or quit } \\
\text { within last } 15 \text { years }\end{array}$ & 53,454 & 1.7 & NR \\
\hline $\begin{array}{l}\text { Infante et al, }{ }^{7} \\
2015\end{array}$ & $\begin{array}{l}\text { Aged } 60-74 \text { years, male, smoker of } \geq 20 \text { pack-years or } \\
\text { quit within } 10 \text { years }\end{array}$ & 2,450 & 4.6 & Mean: 64.6 years \\
\hline Wille et al, 2016 & $\begin{array}{l}\text { Aged } 50-70 \text { years, smoker of } \geq 20 \text { pack-years or exsmoker } \\
\text { who had quit after aged } 50 \text { years, and within } 10 \text { years }\end{array}$ & 4,104 & 1.9 & Mean: 57.9 years \\
\hline Paci et $\mathrm{al}_{,}{ }^{19} 2017$ & $\begin{array}{l}\text { Aged } 55-69 \text { years, smoker or exsmoker ( } \geq 20 \text { pack-years } \\
\text { in the last } 10 \text { years) who had quit no more than } 10 \\
\text { years ago }\end{array}$ & 3,206 & 3.8 & Mean: 60.8 years \\
\hline $\begin{array}{l}\text { Doroudi et al, } 20 \\
2018\end{array}$ & $\begin{array}{l}\text { Aged } 55-74 \text { years, smoker of } \geq 30 \text { pack-years or quit } \\
\text { within last } 10 \text { years }\end{array}$ & 3,318 & 1.6 & NR \\
\hline $\begin{array}{l}\text { Pastorino et al, }{ }^{21} \\
2019\end{array}$ & $\begin{array}{l}\text { Aged } 49-75 \text { years, current smoker } \geq 20 \text { pack-years or quit } \\
\text { within last } 10 \text { years, no cancer in last } 5 \text { years }\end{array}$ & 4,099 & 2.3 & $\begin{array}{l}\text { Median: control, } \\
57 \text { years; screen- } \\
\text { ing, } 58 \text { years }\end{array}$ \\
\hline $\begin{array}{l}\text { Becker et al, }{ }^{18} \\
2020\end{array}$ & $\begin{array}{l}\text { Aged } 50-69 \text { years, } \geq 25 \text { years of smoking } 15 \text { cigarettes } \\
\text { per day, or } \geq 30 \text { years of smoking } 10 \text { cigarettes per day, } \\
\text { or exsmoker who quit no more than } 10 \text { years ago }\end{array}$ & 4,052 & 2.0 & NR \\
\hline $\begin{array}{l}\text { de Koning et al, }{ }^{11} \\
2020\end{array}$ & $\begin{array}{l}\text { Aged } 50-74 \text { years, male, current or former smoker (who } \\
\text { had quit within } 10 \text { years) who smoked }>15 \text { cigarettes } \\
\text { per day for }>25 \text { years or who smoked }>10 \text { cigarettes } \\
\text { per day for }>30 \text { years }\end{array}$ & 15,789 & 3.1 & Median: 58 years \\
\hline
\end{tabular}

control group ranged from $1.6 \%$ to $4.6 \%$. The mean or median age where reported ranged from 57 to 65 years; all but 1 trial had a majority of male participants. All but 1 trial took place in Europe, and the median followup ranged from 5.2 to 10 years. Two trials (the NLST ${ }^{5}$ and its pilot study ${ }^{20}$ ) used chest radiography as the comparator, whereas the remaining 6 used usual care.

\section{Lung Cancer Incidence}

The cumulative incidence ratio of lung cancer in the LDCT-screened vs control groups was 1.21 (95\% CI, 1.06-1.37) for all high-quality trials that provided incidence data. When analysis was limited to the 5 high-quality trials with 8 or more years of follow-up, the cumulative incidence ratio was 1.25 (95\% CI,

Figure 1. Forest plot of lung cancer incidence for trials with 8 or more years of follow-up.

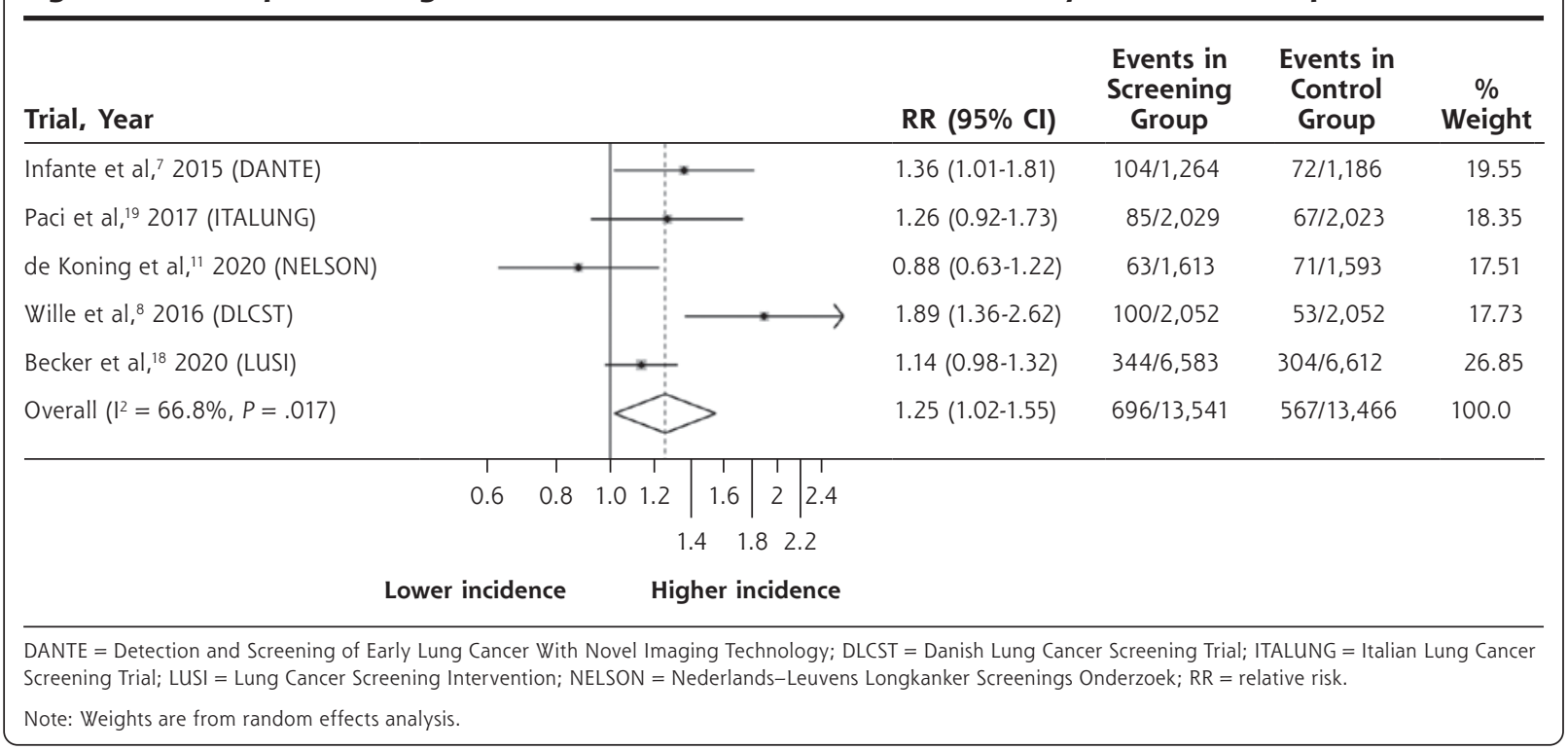




\begin{tabular}{|c|c|c|c|c|c|}
\hline $\begin{array}{l}\text { Sex, \% } \\
\text { Male }\end{array}$ & $\begin{array}{c}\text { Median } \\
\text { Follow-up, } \\
\text { Y }\end{array}$ & $\begin{array}{c}\text { Pack-Years } \\
\text { of Smoking } \\
\text { at Entry }\end{array}$ & $\begin{array}{c}\text { Current } \\
\text { Smokers, } \\
\%\end{array}$ & Country & $\begin{array}{c}\text { Screening } \\
\text { Years }\end{array}$ \\
\hline 59.0 & 6.5 & Median: 48 & 48 & United States & $2002-2007$ \\
\hline 100.0 & 8.35 & $\begin{array}{c}\text { Median: 45; } \\
\text { mean: } 47\end{array}$ & 57 & Italy & 2001-2012 \\
\hline 55.2 & 9.8 & Mean: 36 & 76 & Denmark & $2004-2008$ \\
\hline 64.7 & 8.5 & $\begin{array}{c}\text { Median: } \\
\text { control, 38; } \\
\text { screening, } 40\end{array}$ & 66 & Italy & 2004-2014 \\
\hline 58.6 & 5.2 & Median: 54 & 58 & United States & 2000-2001 \\
\hline 66.3 & 6.2 & $\begin{array}{c}\text { Median: } \\
\text { control, 38; } \\
\text { screening, } 39\end{array}$ & $\begin{array}{c}\text { Control: } 90 \\
\text { screening: } \\
69\end{array}$ & Italy & $2005-2018$ \\
\hline 64.7 & 8.9 & NR & 62 & Germany & $2011-2018$ \\
\hline 83.6 & 10.0 & Median: 38 & 55 & $\begin{array}{l}\text { Netherlands } \\
\text { and Belgium }\end{array}$ & $2003-2015$ \\
\hline
\end{tabular}

Visual inspection of the forest plots showed that incidence was higher in the screening group for 4 of the 5 included trials, and the confidence interval for the cumulative incidence ratio excluded 1.0 .

\section{Lung Cancer-Specific and All- Cause Mortality}

The forest plot for lung cancerspecific mortality is shown in Figure 2. There was a significant reduction in the risk of death with LDCT screening vs control, with a summary estimate of the RR of 0.81 ( $95 \% \mathrm{CI}$, 0.74-0.89). The forest plot for allcause mortality is shown in Figure 3. The risk of death due to any cause was numerically lower in the screened group, but this difference was not statistically significant $(R R=0.96$; 95\% CI, 0.92-1.01). Heterogeneity as measured by the $\mathrm{I}^{2}$ statistic was low for both outcomes at $0 \%$, and, more importantly, visual inspection of the forest plots shows that all of the con-

1.02-1.55). The forest plot for these 5 trials is shown in Figure 1. Although the $\mathrm{I}^{2}$ of $66.8 \%$ suggests a moderate degree of heterogeneity, as noted earlier, this measure is unreliable with a small numbers of studies. ${ }^{16}$ fidence intervals for both outcomes overlapped, another measure of homogeneity. We saw no pattern regarding mortality reduction in relation to the overall rate of lung cancer death in the study population.

Figure 2. Forest plot of lung cancer-specific mortality, sorted by shortest to longest median duration of follow-up.

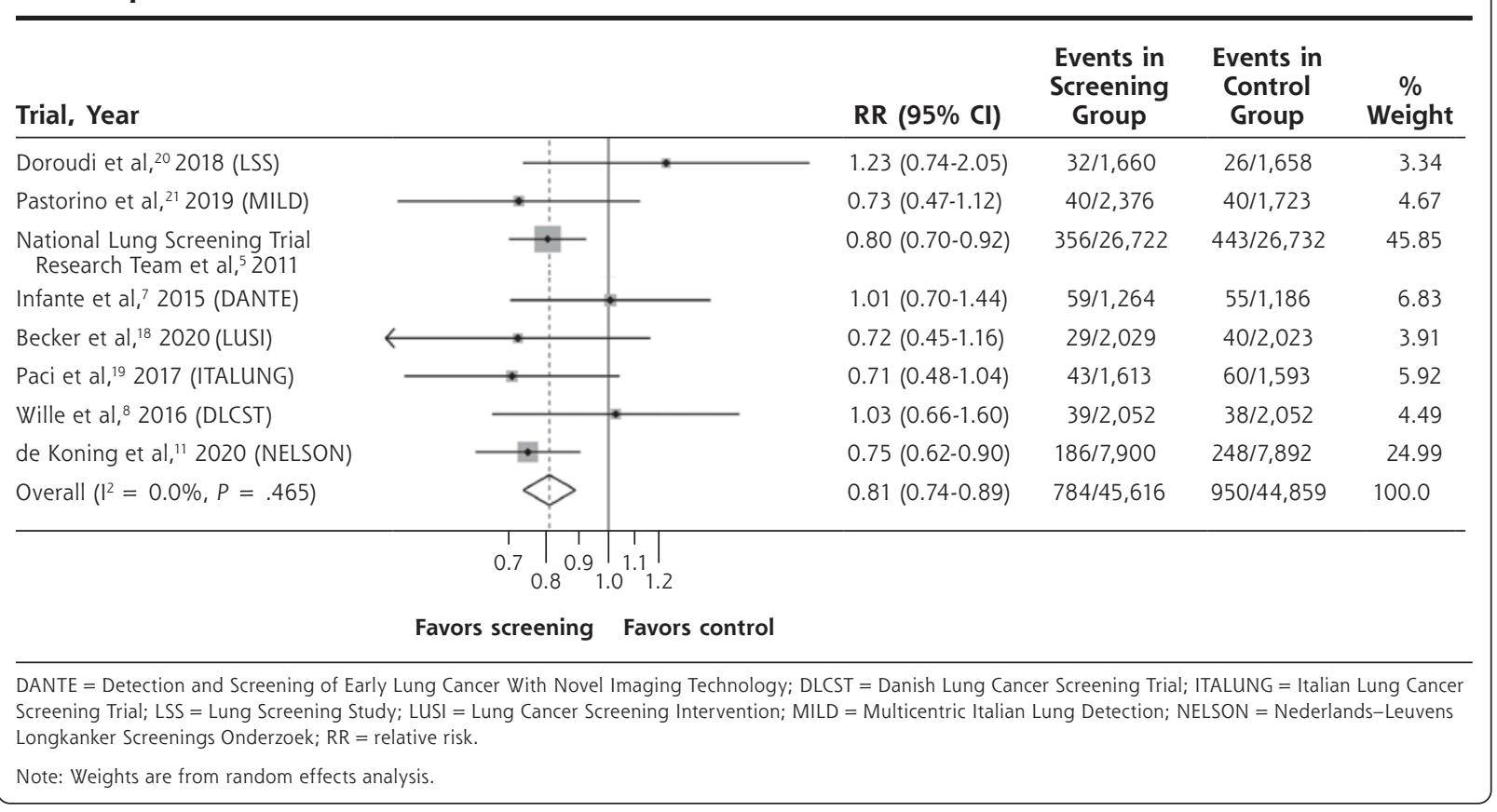


Figure 3. Forest plot of all-cause mortality, sorted by shortest to longest median duration of follow-up.

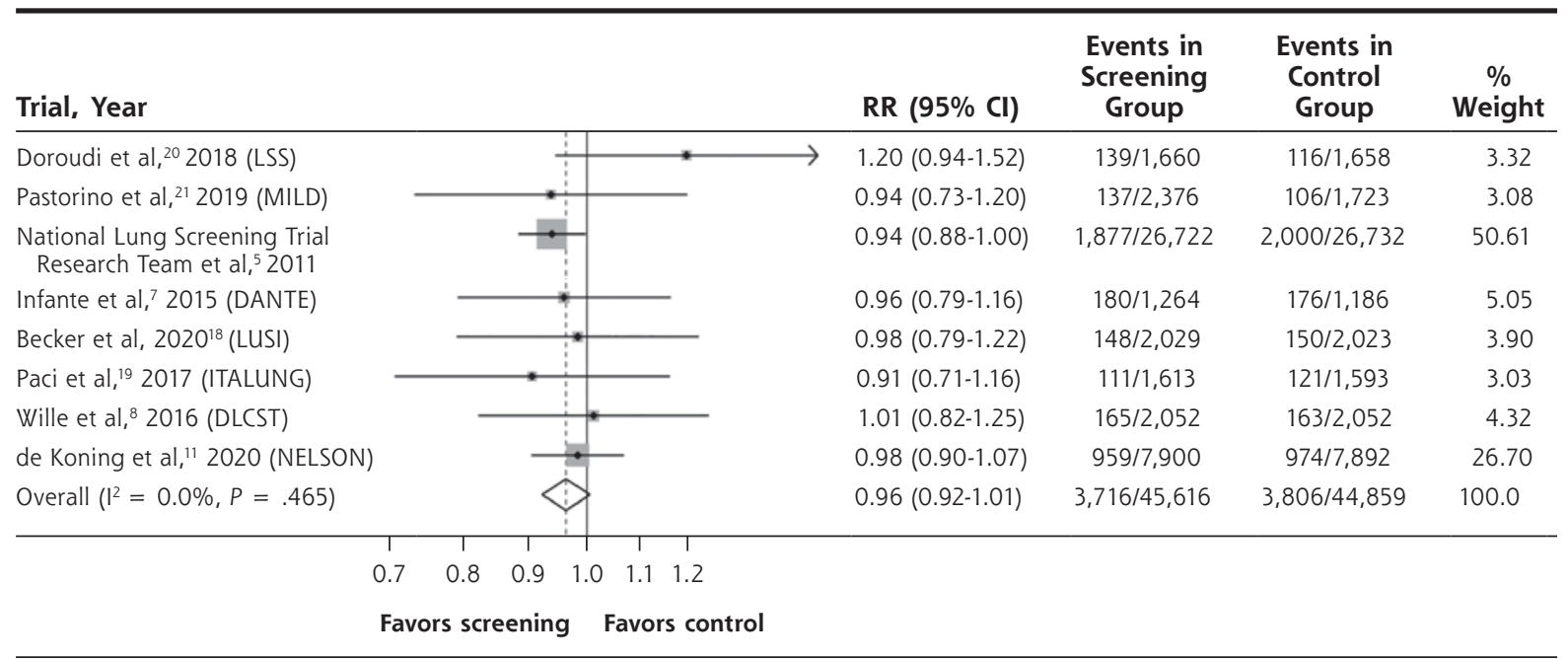

DANTE = Detection and Screening of Early Lung Cancer With Novel Imaging Technology; DLCST = Danish Lung Cancer Screening Trial; ITALUNG = Italian Lung Cancer Screening Trial; LSS = Lung Screening Study; LUSI = Lung Cancer Screening Intervention; MILD = Multicentric Italian Lung Detection; NELSON = NederlandsLeuvens Longkanker Screenings Onderzoek; RR = relative risk.

Note: Weights are from random effects analysis.

\section{Estimation of Absolute Mortality Reduction}

The pooled lung cancer-specific mortality rate in the control group was $2.12 \%$ (950 deaths among 44,859 patients). Applying the summary estimate of relative risk of 0.81 to this mortality rate yielded an estimated lung cancer-specific mortality rate in the screened population of $1.72 \%(2.12 \% \times 0.81)$. Thus, the absolute risk reduction for lung cancer mortality was $0.4 \%(2.12 \%-$ $1.72 \%)$. This reduction corresponds to a number needed to screen to prevent 1 death due to lung cancer of 250 .

The pooled all-cause mortality rate in the control group was $8.48 \%$ (3,806 deaths among 44,859 patients). Applying the summary estimate of the RR of 0.96 (acknowledging that this value was not statistically significant) yielded an estimated all-cause mortality rate in the screened population of $8.14 \%(8.48 \%$ $\times 0.96)$. The absolute risk reduction for all-cause mortality was therefore $0.34 \%(8.48 \%-8.14 \%)$. This reduction corresponds to a number needed to screen to prevent 1 death from any cause of 294 .

\section{DISCUSSION}

Our meta-analysis of 8 high-quality randomized controlled trials of LDCT lung cancer screening found a clinically and statistically significant absolute reduction in lung cancer-specific mortality of $0.4 \%$. Stated another way, 250 patients would have to be screened with this modality to prevent 1 death due to lung cancer over the 5.2 to 10 years of follow-up conducted in these trials.
All-cause mortality was not reduced in a statistically significant manner, although if true, the absolute reduction of $0.34 \%$ would be clinically meaningful. We have previously reported the need for far larger sample sizes to detect a significant reduction in all-cause mortality as opposed to disease-specific mortality. ${ }^{22}$ With a ratio of all-cause mortality to lung cancer-specific mortality of $4(8.48 \%$ vs $2.12 \%)$, one would need a sample size 4 times larger to have the same statistical power as in a study designed to detect a significant reduction in only lung cancer-specific mortality.

Although the absolute reduction in all-cause mortality was not statistically significant, it was of a similar magnitude as the reduction in lung cancer-specific mortality $(0.34 \%$ vs $0.4 \%)$. This similarity is reassuring. Given the occurrence of overdiagnosis, one cannot conclusively rule out substantial unintended harms of LDCT screening, but if present, they do not appear to increase other causes of mortality.

The point estimates of 3 of the 8 trials included in our meta-analysis showed no benefit of LDCT lung cancer screening compared with usual care. ${ }^{7,8,20}$ These were smaller trials (having 3,318 to 4,104 patients), but there is no obvious reason for their findings based on their design or duration of follow-up. It is reassuring that the $95 \%$ confidence interval for all of these trials overlaps with the summary estimate of effect.

Overdiagnosis is recognized as an important potential harm in cancer screening programs, given the ability of modern imaging to detect small, possibly indolent lesions. ${ }^{13,23}$ One way to measure overdiagnosis 
is by comparing incidence rates between screened and unscreened populations with long-term follow-up. Cancers detectable only by screening that never would have become symptomatic are not identified in the unscreened group. We found a $25 \%$ higher incidence of lung cancer in the screening arm of the subset of studies that followed patients for 8 or more years, corresponding to a $20 \%$ rate of overdiagnosis. This rate is consistent with estimates from other studies of lung cancer diagnosis ${ }^{17}$ and also with estimates of the rate of overdiagnosis for breast cancer. ${ }^{13}$ Longer follow-up is needed to ensure that all the lung cancers in the control group that were not detected during the follow-up period to date but that will become symptomatic during a patient's lifetime are detected.

Unfortunately, lung cancer screening has had a very low uptake in the United States. A study from the Centers for Disease Control and Prevention found that only $4.5 \%$ of eligible patients had undergone lung cancer screening, and that many patients were still receiving chest radiography as a screening test. ${ }^{24}$ It is unclear why the uptake is so low. Possible reasons include lack of physician acceptance; the high rate of falsepositives, which could discourage patients over time; and even a perception that resources should not be used on screening for a risk group where risk is defined by a lifestyle choice. Interventions to address this gap between current and optimal screening rates include using navigators to help patients follow up appropriately, embedding guidance in electronic health records, and implementing interventions to better identify eligible patients through use of portals and existing health care data. ${ }^{25}$ Further research, ideally with mixed methods, is needed to understand the reasons for these low screening rates and how to improve them.

The recently published NELSON trial ${ }^{11}$ used a volume-based follow-up protocol and reported a lower rate of false-positives and investigations than the NLST. ${ }^{5}$ Mitigating the potential harms and the need for follow-up testing is another way to improve uptake. It is therefore important that physicians and health systems use standardized protocols designed to minimize harm. Ideally, recruitment for lung cancer screening and implementation should be centrally organized and standardized to ensure adherence to best-evidence protocols and minimization of harms.

Our meta-analysis has several limitations. Although heterogeneity for mortality was low based on the $\mathrm{I}^{2}$ statistic, visual inspection of the forest plots revealed some heterogeneity. This heterogeneity may have been due to differences in the underlying populations, screening protocols, imaging technologies, follow-up protocols, and duration of follow-up. It is reassuring that 5 of the 8 included studies had a point estimate of the RR indicating benefit, and that the 2 largest and longest trials both found a statistically significant reduction in lung cancer mortality. Although the reduction in all-cause mortality was not statistically significant, the existing data were not powered for this outcome, and it is reassuring that the reduction in allcause mortality was consistent with the reduction in lung cancer-specific mortality. The lack of blinding is a limitation but would be difficult to overcome. Failure to blind outcome assessors is more problematic for assignment of cause of death. Again, the consistency of the reduction in lung cancer-specific and all-cause mortality supports the accuracy of the assignment of cause of death. Also, all included trials reported robust procedures for assigning cause of death.

In conclusion, meta-analysis of 8 high-quality randomized trials clearly demonstrates a reduction in lung cancer-specific mortality that is statistically as well as clinically significant. The number needed to screen over 5 to 10 years to prevent 1 lung cancer death was 250 , which compares favorably with that for breast cancer screening in women aged 50 to 59 years (351 women) and aged 60 to 69 years (233 women). ${ }^{26} \mathrm{Mea}$ sures to increase uptake of lung cancer screening and ensure adherence to follow-up protocols based on the best available evidence are needed.

To read or post commentaries in response to this article, see it online at https://www.AnnFamMed.org/content/18/6/545.

Key words: lung cancer; cancer screening; mass screening; low-dose computed tomography; overdiagnosis; public health; preventive medicine; health services

Submitted March 29, 2020; submitted, revised, May 18, 2020; accepted May 26, 2020.

Supplemental materials: Available at https://www.AnnFamMed. org/content/18/6/545/suppl/DC1/.

\section{References}

1. American Cancer Society. Lung cancer statistics. https://www.cancer. org/cancer/lung-cancer/about/key-statistics.html. Accessed Jun 3, 2020.

2. Moss SM, Wale C, Smith R, Evans A, Cuckle H, Duffy SW. Effect of mammographic screening from age 40 years on breast cancer mortality in the UK Age trial at 17 years' follow-up: a randomised controlled trial. Lancet Oncol. 2015;16(9):1123-1132.

3. Bibbins-Domingo K, Grossman DC, Curry SJ, et al; US Preventive Services Task Force. Screening for colorectal cancer: US Preventive Services Task Force recommendation statement. JAMA. 2016; 315(23):2564-2575.

4. Marcus PM, Bergstralh EJ, Fagerstrom RM, et al. Lung cancer mortality in the Mayo Lung Project: impact of extended follow-up. J Natl Cancer Inst. 2000;92(16):1308-1316.

5. National Lung Screening Trial Research Team, Aberle DR, Adams AM, et al. Reduced lung-cancer mortality with low-dose computed tomographic screening. N Engl J Med. 2011;365(5):395-409.

6. Moyer VA; US Preventive Services Task Force. Screening for lung cancer: U.S. Preventive Services Task Force recommendation statement. Ann Intern Med. 2014;160(5):330-338. 
7. Infante M, Cavuto S, Lutman FR, et al; DANTE Study Group. LongTerm follow-up results of the DANTE Trial, a randomized study of lung cancer screening with spiral computed tomography. Am J Respir Crit Care Med. 2015;191(10):1166-1175.

8. Wille MMW, Dirksen A, Ashraf $\mathrm{H}$, et al. Results of the randomized Danish lung cancer screening trial with focus on high-risk profiling. Am J Respir Crit Care Med. 2016;193(5):542-551.

9. Coureau G, Delva F. Dépistage du cancer du poumon chez les fumeurs [Lung cancer screening among the smoker population]. Bull Cancer. 2019;106(7-8):693-702.

10. Huang KL, Wang SY, Lu WC, Chang YH, Su J, Lu YT. Effects of lowdose computed tomography on lung cancer screening: a systematic review, meta-analysis, and trial sequential analysis. BMC Pulm Med. 2019;19(1):126.

11. de Koning $\mathrm{HJ}$, van der Aalst CM, de Jong PA, et al. Reduced lungcancer mortality with volume CT screening in a randomized trial. N Engl J Med. 2020;382(6):503-513.

12. Yang W, Qian F, Teng J, et al; the AME Thoracic Surgery Collaborative Group. Community-based lung cancer screening with low-dose CT in China: Results of the baseline screening. Lung Cancer. 2018; 117:20-26.

13. Esserman LJ, Thompson IM Jr, Reid B. Overdiagnosis and overtreatment in cancer: an opportunity for improvement. JAMA. 2013; 310(8):797-798.

14. Moher D, Liberati A, Tetzlaff J, Altman DG; PRISMA Group. Preferred reporting items for systematic reviews and meta-analyses: the PRISMA statement. BMJ. 2009;339:b2535.

15. Higgins JPT, Altman DG, Gøtzsche PC, et al; Cochrane Bias Methods Group; Cochrane Statistical Methods Group. The Cochrane Collaboration's tool for assessing risk of bias in randomised trials. BMJ. 2011;343:d5928.
16. von Hippel PT. The heterogeneity statistic I(2) can be biased in small meta-analyses. BMC Med Res Methodol. 2015;15:35.

17. Ebell MH, Lin KW. Accounting for the harms of lung cancer screening. JAMA Intern Med. 2018;178(10):1422-1423.

18. Becker N, Motsch E, Trotter A, et al. Lung cancer mortality reduction by LDCT screening-results from the randomized German LUSI trial. Int J Cancer. 2020;146(6):1503-1513.

19. Paci E, Puliti D, Lopes Pegna A, et al; the ITALUNG Working Group. Mortality, survival and incidence rates in the ITALUNG randomised lung cancer screening trial. Thorax. 2017;72(9):825-831.

20. Doroudi M, Pinsky PF, Marcus PM. Lung cancer mortality in the Lung Screening Study Feasibility Trial. JNCI Cancer Spectr. 2018;2(3): pky042.

21. Pastorino $U$, Silva $M$, Sestini $S$, et al. Prolonged lung cancer screening reduced 10-year mortality in the MILD trial: new confirmation of lung cancer screening efficacy. Ann Oncol. 2019;30(7):1162-1169.

22. Dobbin KK, Ebell M. Should we expect all-cause mortality reductions in large screening studies? Br J Gen Pract. 2018;68(671):290-291.

23. Welch HG, Black WC. Overdiagnosis in cancer. J Natl Cancer Inst. 2010;102(9):605-613.

24. Richards TB, Doria-Rose VP, Soman A, et al. Lung cancer screening inconsistent with U.S. Preventive Services Task Force recommendations. Am J Prev Med. 2019;56(1):66-73.

25. Triplette M, Thayer JH, Pipavath SN, Crothers K. Poor uptake of lung cancer screening: opportunities for improvement. J Am Coll Radiol. 2019;16(4 Pt A):446-450.

26. Hendrick RE, Helvie MA. Mammography screening: a new estimate of number needed to screen to prevent one breast cancer death. AJR Am J Roentgenol. 2012;198(3):723-728.

\section{CHANGE-OF-ADDRESS FORM \\ FAMILY MEDICINE}

Please complete this form and mail to the following address or fax to Annals Circulation at 913-906-6080:

Annals of Family Medicine, Circulation Department, 11400 Tomahawk Creek Pkwy, Leawood, KS 66211-2680

Check if member of sponsoring organization:

\section{$\square \mathrm{AAFP} \square \mathrm{ABFM} \square \mathrm{STFM} \square \mathrm{ADFM}$ \\ $\square$ AFMRD $\square$ NAPCRG $\square$ CFPC}

ID number from label on your journal cover

OLD Information (Please print.)

\begin{tabular}{ll}
\hline Name \\
\hline Company (if applicable) \\
\hline Address (Street plus Apt or Ste) \\
\hline City & Postal Code (9-digit ZIP for US) \\
\hline Country & Fax \\
\hline Telephone & \\
\hline E-Mail &
\end{tabular}

NEW Information (Please print.)

\begin{tabular}{lc}
\hline Name \\
\hline Company (if applicable) \\
\hline Address (Street plus Apt or Ste) \\
\hline City & Postal Code (9-digit ZIP for US) \\
\hline Country & Fax \\
\hline Telephone & \\
\hline E-Mail &
\end{tabular}

